\title{
Gemma Carney \& Paul Nash (2020). Critical questions for Ageing Societies. Bristol: Policy Press, 234 pp. ISBN 978-1447351580 (paperback)
}

\author{
ReVieWed by Aled Singleton*
}

This volume responds to nine questions about ageing societies posed by students to the authors Gemma Carney and Paul Nash. To that end these topics, such as retirement, politics and gender, dictate the overall flow and direction of the book. From the perspective of a more experienced academic or researcher this may lead to familiar ground which has been surveyed in many other books. However, in the end we arrive at something which is more subtle and incremental; for example the larger concepts of political economy, language and post-structuralism are only made apparent in the last five pages of the main text (pp. 145-149). Moreover, to read this book you have to put yourself in the position of younger readers - presumably who are largely at undergraduate level and born around the time of the Millennium - to understand how they sense the world.

Based on the concept that ontological frameworks differ between older and younger students, this review focuses on four elements critical to this book: firstly an explanation of population ageing; secondly the terminology of 'birth cohorts' and 'generations' as being different; thirdly the 
International Journal of Ageing and Later Life

attention paid to neoliberalism; and finally the relevance of the cultural turn in academic research and methodology.

\section{Central premise and style}

Gemma Carney and Paul Nash use their experience of teaching, both in the UK and in the USA, to frame this book. In the preface, they describe the format as "perhaps risky" but contend at the same time that it could offer greater "relevance and timeliness." As such, the chapters respond to topics decided by students, with group activities and multiple choice questions at the end of each section. The same questions have also been collated online. The latter resource is useful, as is providing the email addresses for each of the two authors. The appendixes contain some further resources, including a simple demonstration of how to visually represent age distributions with population pyramids (pp. 167-175).

The first chapter explains the three factors that drive ageing, which are, broadly, falling birth rates, living longer and less immigration. The deeper one gets into the work, the more the reader senses that these factors change over time. Overall, the style is fairly conversational and there is a feeling that both authors are driven by their desire to confront ageism and ageist language associated with older people.

\section{Birth cohort and generations}

The authors explain that generations are connected to time and social structure. In particular, they cite Mannheim's premise that "a generation can only participate in a temporally limited section of the historical process" (p. 100). We then learn about the temporal dimension over the following three pages: that a generation can contain birth cohorts who are born over periods of perhaps 5 or 10 years. Moreover, we appreciate that the boundaries between generations can be linked to major events such as wars, recessions and so forth. As such, generations can differ in terms of expectations and standards of behaviour. Having given time to explain that the concept of a generation is a relative, my one criticism is that the analysis of 'neoliberalism' - which appears throughout the book - could have been set in a temporal context just as were generations. 


\section{Neoliberalism}

Pretty much from the offset this book references neoliberalism and brings forward evidence of policy - such as housing and health care - changing from social provision towards individualism. For example, they chart this agenda emerging in the 1970s and properly taking effect from the 1980s on both sides of the Atlantic because of British Prime Minister Margaret Thatcher and US President Ronald Reagan. There is one case study about the cost of care (p. 43) which does not provide enough depth or nuance to convey to neoliberalism. However, the ideas start to fit into a wider context when the authors reveal that the "politics of post-war Britain were collective and cohesive" and that neoliberalism of the past thirty years has made a "sustained onslaught on this collective mentality" (pp. 112-113). Though this latter statement may be true, it is perhaps hard to grasp for people born since the collectivist-individualist battles of the 1970s and 1980s.

In my view, it helps to put neoliberalism into the context of place and time. For example Stephen Metcalf's essay describes neoliberalism as "the idea that swallowed the world" (The Guardian, 2017) and is "...a premise that, quietly, has come to regulate all we practise and believe: that competition is the only legitimate organising principle for human activity." As such I think that Critical Questions for Ageing Societies could have described how neoliberalism has gained power over some decades and has therefore influenced generations and birth cohorts differently. To that end, this book potentially could use biographical or pen picture examples of provision in housing or health care for people born in different periods of time.

\section{Cultural turn}

The book adheres to the central premise of answering the student questions and is not necessarily aimed at deeper questions of theory or epistemology - which is to say that research and method is not the main focus. However, there is a chapter that is useful in terms of exploring what it means to live a long life. The authors cite examples of approaches to understand ageing turning away from biomedical or political economy influences (pp. 125-127). The culture turn includes the work of Gilleard and 
International Journal of Ageing and Later Life

Higgs on topics such as sexual orientation, identity and consumption, Gullette's writing on narrative or Twigg's various works on embodiment. Carney and Nash argue that bringing human experience "back into the foreground" and using examples about everyday life allows forms of evidence, approaches and theories to come forward (p. 137). This writing on what it means to live a long life bridges into the final chapter where some of the bigger theoretical concepts of post-structuralism and language are outlined. Effectively, it is at the end where the authors give a taste of how a post-graduate research project could be compiled. I think that this gradual approach works.

\section{Conclusions}

Through this work we get to know something about the authors and what has motivated them to write this book. To that end I think that the desire to shape it around the questions posed by students has succeeded. Throughout there is a consistent desire to break down ageism and also to question topics like intergenerational conflict. Apart from the examples that I have explored in detail, there are also investigations into sexuality, gender, pensions and the problems of providing care. However I would have welcomed a more nuanced critique of neoliberalism. Given that generations and the cultural turn were explained in some detail, perhaps some small biographical narratives could explain how policy has affected the lifecourse of people born in different decades? Such examples would help explain how life could be different in terms of social care, pensions, housing and much more.

\section{References}

The Guardian. (2017, August 18). Neoliberalism: The idea that swallowed the world. Retrieved November 05, 2020, from The Guardian: https://www.theguardian.com/news/2017/aug/18/neoliberalismthe-idea-that-changed-the-world 